\title{
Editorial
}

\section{Excuse the interruption: How marketing still gets attention}

Journal of Direct, Data and Digital Marketing Practice (2015) 17, 75-76. doi:10.1057/dddmp.2015.48

Since digital channels passed the tipping point and became the predominant routes to market, a critical question has been discussed by marketers: Do the long-established principles of marketing still hold true online? Probably the single most important issue is whether interruption marketing can be as effective in channels where the consumer is actively engaged with tasks, such as search, posting and networking.

Advertising by its very nature is commercial information that sits between the consumer and the content they are looking at. As the key source of funding for most of the services that digitally native consumers take for granted - social networks, search engines, photo-sharing sites - it is a matter of fundamental importance to all concerned whether ads are effective in getting attention in these new environments.

'The art of mistiming: How interruptions make mobile coupon campaigns effective', one of three whitepapers in this issue, offers an important insight into the way consumers respond to ads in a context where they are engaged in a specific activity. Despite many advertisers pulling back from interruptive, awareness-building display ads, this study shows that they can be both welcome and effective in the right situation. Loyal customers using a brand's app can respond with surprise and delight, even deepening their use of the app and relationship with the brand.

Consumers who are using food-related apps, meanwhile, can show a similarly positive response to stimulus ads that offer alternative propositions, whether price- or health-based, although this effect is strongest among a specific group of individuals who are engaged with both technology and food. 'Mobile app-etite: Consumer attitudes toward and use of mobile technology in the context of eating behaviour' reveals that brands can meet their commercial and societal goals, such as encouraging healthy eating, if they get the mobile marketing strategy right.

Reviews have become a major area of concern for many marketers who wrestle with the issue of opening up their brand platform to user-generated content that may be either positive or negative. If you allow customers to self-report the unvarnished truth about their experience of a product or service, how will it impact on sales? 'Social media marketing evaluation using social network comments as an indicator for identifying consumer purchasing decision effectiveness' offers a measurement framework to assess exactly this question, showing whether reviews really do affect buying decisions.

In the new world of the mobile consumer, there are many more influences on behaviour than the ones that marketers bring to bear. The voice of other consumers can be far more influential via reviews, comments, shared photos and the like. The fear is that marketing's message is just a whisper in this noisy context, struggling to deliver the brand's truth and gain attention.

Reading these three studies shows that there is still an important role for marketing. Indeed, getting the message right and placing it in an appropriate context can improve the consumer's experience and extend their relationship with a brand. That has always been the goal of marketing and it remains unchanged, despite the transformational effect of technology, mobile and social channels.

Assuming marketers can read the indicators correctly, they should be able to formulate strategies that retain traction with consumers. Persuading their organization of the need for new approaches to do that increasingly relies on a new skill-set — that of data storytelling. For many marketers, this is not a natural 


\section{安. Editorial}

ability, but rather one they need to develop. As explained in the opinion article, 'Managing customer insight creatively through storytelling', there are clear and practical steps that any marketer can take to build their competency in this new area of practice.

It is just one more example of how marketing needs to adapt to the new environment and behaviours it encounters, while at the same time retaining the core skills and effectiveness it has built over decades. The good news is that, regardless of the innovations taking place, there is no fundamental interruption to the way marketing acts on the consumer.

David Reed 